Article

\title{
Bone Protective Effect of Extra-Virgin Olive Oil Phenolic Compounds by Modulating Osteoblast Gene Expression
}

\author{
Lucía Melguizo-Rodríguez ${ }^{1,2}$, Francisco Javier Manzano-Moreno ${ }^{2,3}$, Rebeca Illescas-Montes ${ }^{1,2}$, \\ Javier Ramos-Torrecillas ${ }^{1,2} \mathbb{D}$, Elvira de Luna-Bertos ${ }^{1,2} \mathbb{D}$, Concepción Ruiz $1,2,4, * \mathbb{D}$ and \\ Olga García-Martínez 1,2 \\ 1 Biomedical Group (BIO277), Department of Nursing, Faculty of Health Sciences, University of Granada, \\ Avda. Ilustración 60, 18016 Granada, Spain \\ 2 Instituto Investigación Biosanitaria, ibs.Granada, C/ Doctor Azpitarte 4, $4^{\mathrm{a}}$ planta, 18012 Granada, Spain \\ 3 Biomedical Group (BIO277), Department of Stomatology, School of Dentistry, University of Granada, \\ Colegio Máximo, Campus Universitario de Cartuja, 18071 Granada, Spain \\ 4 Institute of Neuroscience, University of Granada, Centro de Investigación Biomédica (CIBM). Parque de \\ Tecnológico de la Salud (PTS) Avda. del Conocimiento S/N, 18016 Armilla, Granada, Spain \\ * Correspondence: crr@ugr.es; Tel.: +34-958248039; Fax: +34-958-24-28-94
}

Received: 26 June 2019; Accepted: 23 July 2019; Published: 25 July 2019

\begin{abstract}
The phenolic compounds of extra-virgin olive oil can act at various levels to protect individuals against cardiovascular and neurodegenerative diseases, cancer, and osteoporosis, among others. Polyphenols in extra-virgin olive oil can stimulate the proliferation of osteoblasts, modify their antigen profile, and promote alkaline phosphatase synthesis. The objective of this work was to determine the effect of different extra-virgin olive oil phenolic compounds on the gene expression of osteoblast-related markers. The cells of the MG63 osteoblast line were cultured for $24 \mathrm{~h}$ with $10^{-6} \mathrm{M}$ of the phenolic compounds ferulic acid, caffeic acid, coumaric acid, apigenin, or luteolin. The expression of studied markers was quantified using quantitative real-time polymerase chain reaction (q-RT-PCR). The expression by MG63 osteoblasts of growth and differentiation/maturation markers was modified after $24 \mathrm{~h}$ of treatment with $10^{-6} \mathrm{M}$ of the phenolic compounds under study, most of which increased the gene expression of the transforming growth factor $\beta 1$ (TGF- $\beta 1$ ), TGF- $\beta$ receptor 1,2 and 3 (TGF- $\beta$ R1, TGF- $\beta$ R2, TGF- $\beta$ R3), bone morphogenetic protein 2 and 7 (BMP2, BMP7), run-related transcription factor 2 (RUNX-2), Alkaline phosphatase (ALP), Osteocalcin (OSC), Osterix (OSX), Collagen type I (Col-I) and osteoprotegerin (OPN). The extra-virgin olive oil phenolic compounds may have a beneficial effect on bone by modulating osteoblast physiology, which would support their protective effect against bone pathologies.
\end{abstract}

Keywords: extra virgin olive oil; phenolic compounds; gene expression; osteoblast; genetic profile

\section{Introduction}

The Mediterranean diet is a balanced and varied nutritional model characterized by the consumption of fruit, vegetables, polyunsaturated fats (e.g., from fish), and monounsaturated fats (e.g., from dried fruit, nuts, and olive oil) [1]. Extra-virgin olive oil (EVOO), a key component of this diet, contains more than 30 phenolic compounds with antioxidant capacities [2,3]. The chemical composition of EVOO comprises a majority fraction, mainly triglycerides, and a minority fraction that includes phenolic compounds [4]. EVOO appears to meet the definition of a functional food proposed by the International Life Sciences Institute (ILSI Europe) in 1993, given its nutritional properties and its beneficial effect on one at least one function of the organism [5]. It has been reported that the phenolic 
compounds in EVOO can protect individuals against cardiovascular and neurodegenerative diseases, cancer, and osteoporosis, among others [6-9].

Osteoporosis is characterized by bone mass loss and bone microarchitecture impairment [10] and affects approximately 200 million women worldwide [11], causing more than 8.9 million fractures a year [12]. It results from an imbalance between bone formation and resorption mechanisms [13,14], with the osteoblast playing a key role as the main cell promoting bone tissue formation and repair. Osteoblasts derive from mesenchymal cells, and their physiology and activity are widely influenced by endocrine, autocrine, and paracrine factors [15].

Phenolic compounds in olive oil, such us apigenin, luteolin, coumaric acid, ferulic acid and caffeic acid, have been found to increase the proliferative capacity and differentiation of osteoblasts, among other effects, being $10^{-6} \mathrm{M}$ of the most active dose between the studied concentrations [6,16,17]. However, the underlying mechanisms of their action remain unknown. Studies of markers related to bone resorption (e.g., osteoprotegerin [OPG] and OPG/receptor activator of nuclear factor-kappaB ligand [RANKL]) have demonstrated that phenolic compounds in EVOO inhibited osteoclastogenesis, and therefore bone tissue loss $[18,19]$. It has also been observed that the EVOO phenolic compound oleuropein favored bone preservation and repair by increasing the expression of genes related to osteoblastogenesis, including RUN-related transcription factor 2 (RUNX-2), osterix (OSX), collagen type I (COL-I), osteocalcin (OSC), and alkaline phosphatase (ALP) [20], thereby favoring bone preservation and repair.

The aim of this study was to explore the action mechanisms that underlie the protective effects on bone tissue of EVOO phenolic compounds by studying the gene expression of osteoblast-related markers, including bone morphogenetic proteins 2 and 7 (BMP-2 and BMP-7), transforming growth factor (TGF)- $\beta 1$, TGF- $\beta$ receptors (TGF- $\beta$ R1, TGF- $\beta$ R2; TGF- $\beta$ R3), RUNX-2, ALP, COL-I, OSX, OPG and OSC, using the MG63 osteoblastic cell line.

\section{Material and Methods}

\subsection{Chemical Compounds}

Caffeic acid, ferulic acid, coumaric acid, luteolin and apigenin were purchased from Sigma-Aldrich (St. Louis, MO, USA) and kept at $-20^{\circ} \mathrm{C}$. The aliquots of these phenolic compounds were prepared from mother solutions to achieve the appropriate concentration for each treatment. All solvents used were of analytical or HPLC grade (Sigma-Aldrich), and the water was of Milli-Q quality (Millipore Corp, Bedford, MA, USA).

\subsection{Cell Culture}

The MG63 osteoblast cell line, derived from a 14-year-old Caucasian male, was obtained from the ATCC. The cells were preserved in Dulbecco's Modified Eagle Medium (DMEM; Invitrogen Gibco Cell Culture Products, Carlsbad, CA, USA) with $100 \mathrm{IU} / \mathrm{mL}$ penicillin (Lab Roger SA, Barcelona, Spain), $50 \mu \mathrm{g} / \mathrm{mL}$ gentamicin (Braun Medical SA, Jaen, Spain), $2.5 \mu \mathrm{g} / \mathrm{mL}$ amphotericin B (Sigma, St Louis, MO, USA), 1\% glutamine (Sigma), and 2\% HEPES (Sigma) supplemented with 10\% fetal bovine serum (FBS) (Gibco, Paisley, UK). The cultures were kept at $37^{\circ} \mathrm{C}$ in a humidified atmosphere of $95 \%$ air and $5 \%$ CO2. The cells were separated from the culture flask using $5 \mathrm{~mL}$ of a solution of $0.05 \%$ Trypsin (Sigma) and $0.02 \%$ ethylenediaminetetraacetic acid (EDTA) (Sigma) followed by their neutralization and re-suspension in a complete culture medium with $10 \%$ FBS.

\subsection{Treatments}

The osteoblasts were seeded at $1 \times 10^{4}$ cells/ml per well into a 24-well plate (Falcom, Becton Dickinson Labware, Franklin Lakes, NJ, USA) and cultured at $37^{\circ} \mathrm{C}$ in a humidified atmosphere of $95 \%$ air and $5 \% \mathrm{CO}_{2}$ until a $80 \%$ of confluence of the well was reached. Then, the media was replaced with DMEM containing phenolic compounds treatment at $10^{-6} \mathrm{M}$. All experiments included cells incubated under the 
same conditions without treatment compounds as an internal control. Three separate experiments were performed for each treatment and at least every experiment was performed in triplicate.

\subsection{RNA Extraction and cDNA Synthesis (Reverse Transcription)}

The mRNA was extracted from the cells by a silicate gel technique using the Qiagen RNeasy extraction kit (Qiagen Inc., Hilden, Germany), which includes a DNAse digestion step. The amount of extracted mRNA was measured by UV spectrophotometry at $260 \mathrm{~nm}$ (Eppendorf AG, Hamburg, Germany), and contamination with proteins was determined according to the 260/280 ratio. An equal amount of RNA ( $1 \mu \mathrm{g}$ total RNA in $40 \mu \mathrm{L}$ total volume) was reverse-transcribed to cDNA and amplified by PCR with the iScript ${ }^{\mathrm{TM}}$ CDNA Synthesis Kit (Bio-Rad laboratories, Hercules, CA, USA), following the manufacturer's instructions.

\subsection{Real-Time Polymerase Chain Reaction (RT-PCR)}

The mRNA of RUNX-2, OSX, OSC, COL-I, BMP-2, BMP-7, TGF $\beta 1$, TGF $\beta-R 1$, TGF $\beta-R 2$ and TGF $\beta$-R3 was detected with primers designed using the NCBI-nucleotide library and Primer3-design (Table 1). All primers had been matched to the mRNA sequences of the target genes (NCBI Blast software). The final results were normalized using ubiquitin C (UBC), peptidylprolyl isomerase A (PPIA), and ribosomal protein S13 (RPS13) as stable housekeeping genes [21].

Table 1. Primer sequences for the amplification of cDNA by real-time PCR.

\begin{tabular}{|c|c|c|c|}
\hline Gene & Sense Primer & Antisense Primer & Amplicon (bp) \\
\hline TGF $\beta 1$ & 5'-TGAACCGGCCTTTCCTGCTTCTCATG-3' & 5'-GCGGAAGTCAATGTACAGCTGCCGC-3' & 152 \\
\hline TGF $\beta-R 1$ & 5'-ACTGGCAGCTGTCATTGCTGGACCAG-3' & 5'-CTGAGCCAGAACCTGACGTTGTCATATCA-3' & 201 \\
\hline TGF $\beta-R 2$ & 5'-GGCTCAACCACCAGGGCATCCAGAT-3' & 5'-CTCCCCGAGAGCCTGTCCAGATGCT-3' & 139 \\
\hline TGF $\beta-$ R3 & 5'-ACCGTGATGGGCATTGCGTTTGCA-3' & 5'-GTGCTCTGCGTGCTGCCGATGCTGT-3' & 173 \\
\hline RUNX-2 & 5'-TGGTTAATCTCCGCAGGTCAC-3' & 5'-ACTGTGCTGAAGAGGCTGTTTG-3' & 143 \\
\hline OSX & 5'-TGCCTAGAAGCCCTGAGAAA-3' & 5'-TTTAACTTGGGGCCTTGAGA-3' & 205 \\
\hline BMP2 & 5'-TCGAAATTCCCCGTGACCAG-3' & 5'-CCACTTCCACCACGAATCCA-3' & 142 \\
\hline BMP7 & 5'-CTGGTCTTTGTCTGCAGTGG-3' & 5'-GTACCCCTCAACAAGGCTTC-3' & 202 \\
\hline COL-I & 5'-AGAACTGGTACATCAGCAAG-3' & 5'-GAGTTTACAGGAAGCAGACA-3' & 471 \\
\hline OSC & 5'-CCATGAGAGCCCTCACACTCC-3' & 5'-GGTCAGCCAACTCGTCACAGTC-3' & 258 \\
\hline ALP & 5'-CCAACGTGGCTAAGAATGTCATC-3' & 5'-TGGGCATTGGTGTTGTACGTC-3' & 175 \\
\hline RANKL & 5'-ATACCCTGATGAAAGGAGGA-3' & 5'-GGGGCTCAATCTATATCTCG-3' & 202 \\
\hline OPG & 5'-ATGCAACACAGCACAACATA-3' & 5'-GTTGCCGTTTTATCCTCTCT-3' & 198 \\
\hline
\end{tabular}

\subsection{Statistical Analysis}

Further, SPSS 22.0 (IBM, Chicago, IL, USA) was used for statistical analyses. The mRNA levels were expressed as the means \pm standard deviation (SD). The multiple analysis of variance was applied for data comparisons, considering $p<0.05$ to be significant. All studies were conducted in triplicate.

\section{Results}

3.1. Effect of Phenolic Compounds on Gene Expression of TGF $\beta 1$ and its Receptors (TGF $\beta-R 1, T G F \beta-R 2$, and $T G F \beta-R 3)$

The treatment of the MG63 osteoblast line with $10^{-6} \mathrm{M}$ caffeic acid, ferulic acid, coumaric acid, apigenin, or luteolin for $24 \mathrm{~h}$ significantly increased the expression of TGF $\beta 1$ and its receptor TGF $\beta$-R1, as observed in Figure 1. The expression of receptor TGF $\beta-R 2$ significantly increased by the treatment with all phenolic compounds, except for luteolin, which had no significant effect with respect to untreated control cells. The expression of receptor TGF $\beta-\mathrm{R} 3$ was significantly increased by the treatment with all phenolic compounds, except for luteolin and coumaric acid (See Supplementary Table S1). 
A

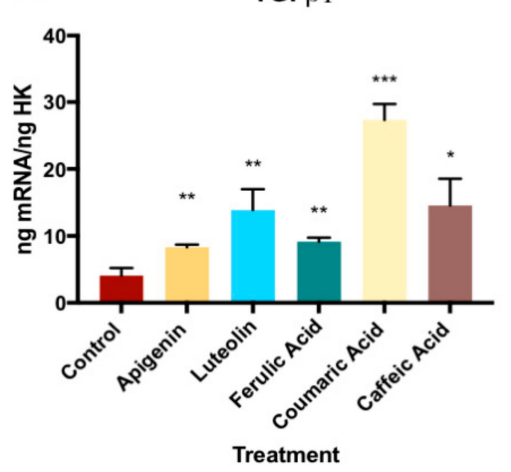

C

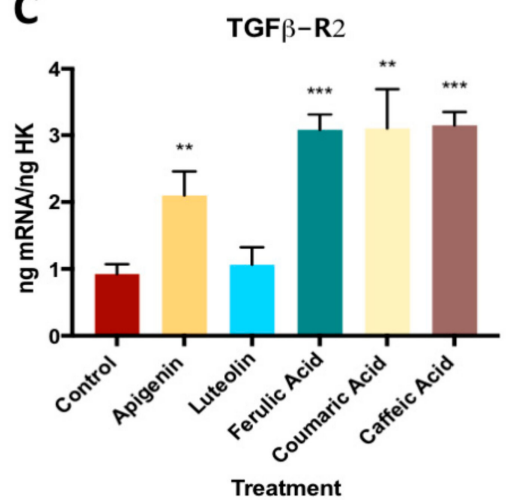

B TGFB-R1

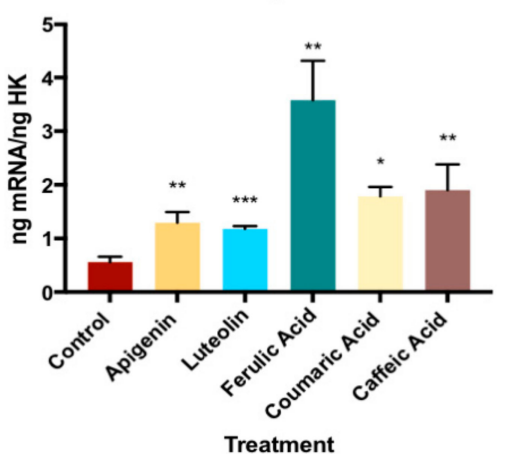

D
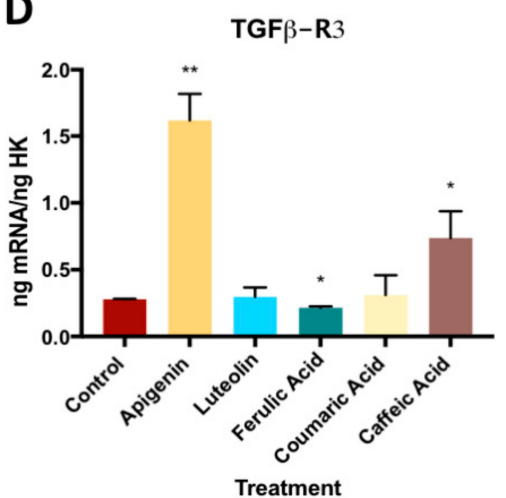

Figure 1. The effect of phenolic compounds on gene expression of TGF $\beta 1$ and its receptors (TGF $\beta$-R1, TGF $\beta$-R2, and TGF $\beta-$ R3). ${ }^{*} p<0.05,{ }^{* *} p<0.005,{ }^{* * *} p<0.001$. TGF- $\beta 1$ : Transforming growth factor $\beta 1$, TGF- $\beta$ receptor 1,2 and 3 (TGF- $\beta$ R1, TGF- $\beta$ R2, TGF- $\beta$ R3).

\subsection{Effect of Phenolic Compounds on Gene Expression on BMP2 and BMP7}

Figure 2 depicts the effect of the treatment with $10^{-6} \mathrm{M}$ of each phenolic compound on the gene expression of BMP2 and BMP7 by MG63 cells. As observed, the gene expressions of both BMP2 and BMP7 were significantly increased versus the controls by the treatment with each compound, except for the expression of BMP2 by luteolin treatment (See Supplementary Table S1).

A

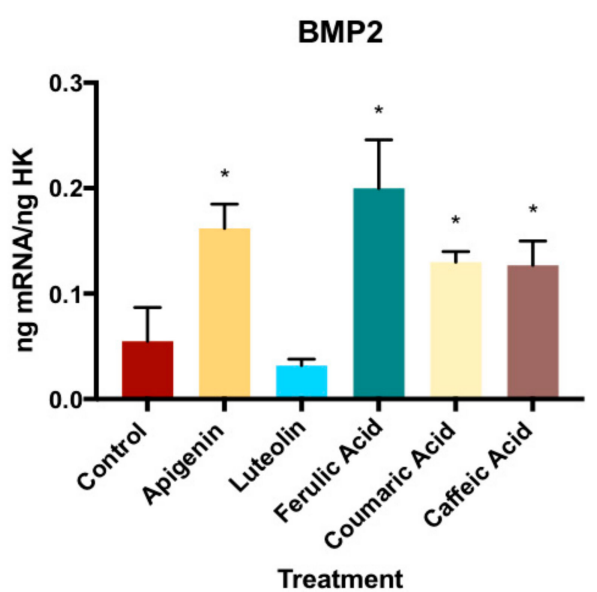

B

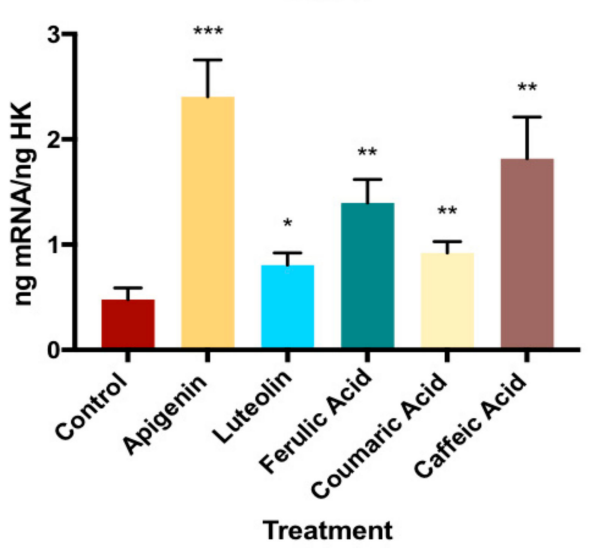

Figure 2. The effect of phenolic compounds on gene expression of BMP2 and BMP7. ${ }^{*} p<0.05,{ }^{* *} p<$ $0.005,{ }^{* * *} p<0.001$. Bone morphogenetic proteins 2 and 7 (BMP-2 and BMP-7). 


\subsection{Effect of Phenolic Compounds on Gene Expression of OPG- RANKL Complex}

As shown in Figure 3, the RANKL expression by the MG63 cells increased after the treatment with $10^{-6} \mathrm{M}$ of each phenolic compound, and their OPG expression was significantly increased by the treatment with apigenin, ferulic acid, or coumaric acid, but not by the treatment with luteolin or caffeic acid. Thus, the OPG-RANKL complex is increased only with apigenin and coumaric acid treatment (See Supplementary Table S1).

A

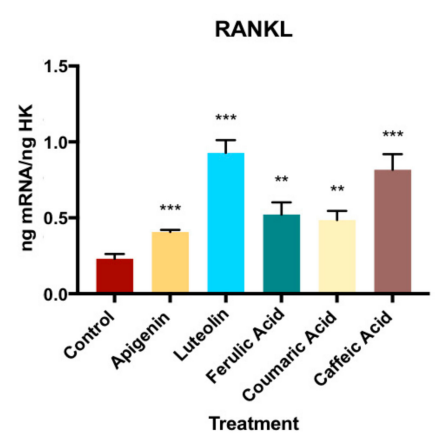

B

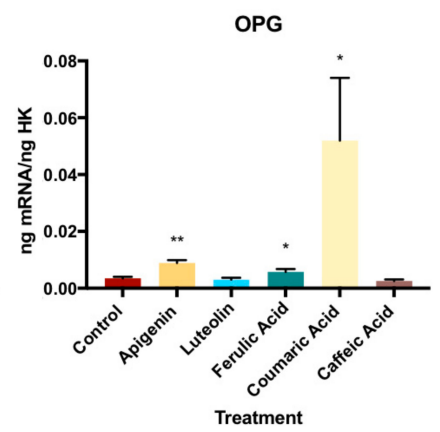

Figure 3. The effect of phenolic compounds on gene expression of OPG-RANKL complex. ${ }^{*} p<0.05,{ }^{* *} p$ $<0.005,{ }^{* * *} p<0.001$. OPG- RANKL: Osteoprotegerin- receptor activator of nuclear factor-kappaB ligand.

\subsection{Effect of Phenolic Compounds on the Gene Expression of RUNX-2, ALP, COL-I, OSX and OSC}

Figure 4 displays the q-RT-PCR results for the expression of osteoblast differentiation markers RUNX-2, ALP, COL-I, OSX, and OSC. The treatment with each phenolic compound increased the expression of all markers, except for COL-I, which was not affected by caffeic acid treatment, and RUNX-2, which was not affected by apigenin treatment (See Supplementary Table S1).
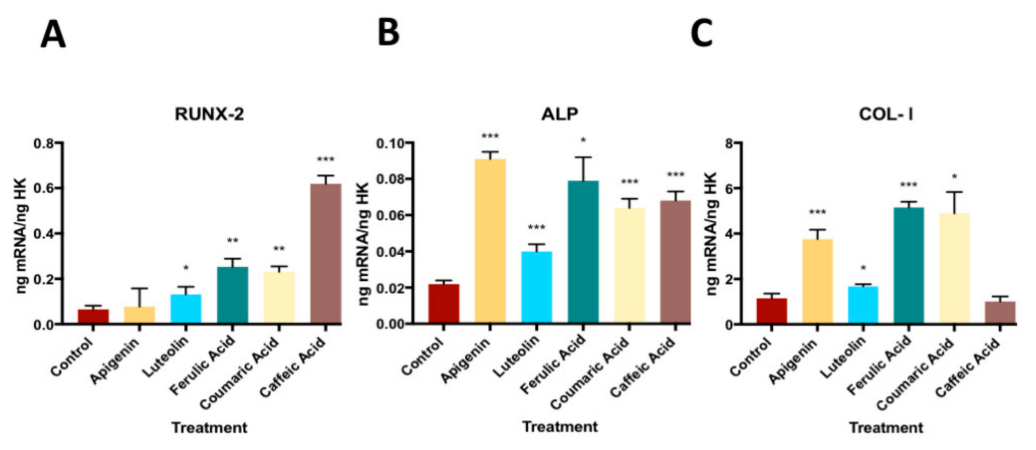

D

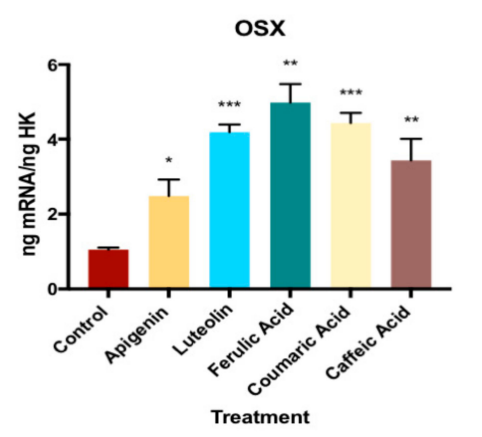

E

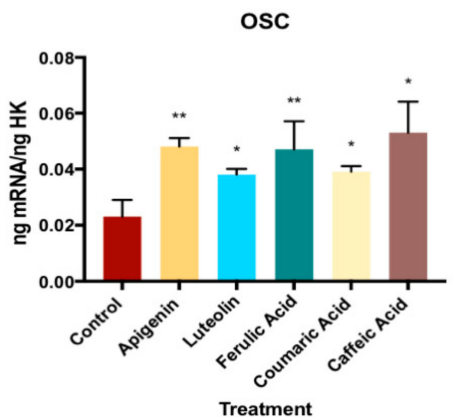

Figure 4. The effect of phenolic compounds on the gene expression of RUNX-2, ALP, COL-I, OSX, and OSC. ${ }^{*} p<0.05,{ }^{* *} p<0.005,{ }^{* * *} p<0.001$. RUNX-2: Run-related transcription factor 2, ALP: Alkaline phosphatase, COl-I: Collagen type I, OSX: Osterix, OSC: Osteocalcin. 


\section{Discussion}

This study found that treatment for $24 \mathrm{~h}$ with $10^{-6} \mathrm{M}$ of caffeic acid, ferulic acid, coumaric acid, apigenin, or luteolin, phenolic compounds present in EVOO changes the expression of growth and differentiation markers by MG63 osteoblasts. Although others phenolic compounds are present in olive oil, such as oleuropein aglycone, oleacein, oleocanthal, hydroxytyrosol and tyrosol [22], the present study only included those compounds and the dose that had a significant effect on growth, differentiation and the antigenic profiles of the MG63 cell line $[6,16,17]$. These findings indicate that bone physiology may be modulated by the phenolic compounds in EVOO, supporting previous observations on their action on osteoblasts at different levels, favoring bone tissue regeneration.

The expression of TGF $\beta 1$ and its receptors was increased by treatment with each phenolic compound except for coumaric acid, which did not change the expression of TGF $\beta$-R2 or TGF $\beta$-R3, and luteolin, which had no effect on TGF $\beta-$ R3 expression. The TGF- $\beta$ superfamily, which includes TGF- $\beta$ isoforms 1,2, and 3, BMPs, activins, and nodal proteins, is a set of transmembrane glycoproteins involved in the signaling cascade that regulates osteoblast differentiation and mineralization [23-25]. Moderate doses of TGF- $\beta(1 \mathrm{ng} / \mathrm{mL}$ and $10 \mathrm{ng} / \mathrm{mL})$ have been found to improve the proliferation and differentiation of osteoblasts [26,27]. An increased expression of this marker has also been reported in osteoblasts treated with other bone tissue regenerative therapies [23,28,29].

BMPs, of which more than 20 have been identified, stimulate bone tissue regeneration and bone cell differentiation, as demonstrated by their effects on ALP and the expression of COL-I, OSC, and OPN, among other cell differentiation markers [30,31]. In the present study, the expression of both BMP2 and BMP7 was higher after treatment for $24 \mathrm{~h}$ with $10^{-6} \mathrm{M}$ of each phenolic compound except for luteolin, which only increased the expression of BMP7. These findings are consistent with the results obtained for phenolic compounds in other vegetables. For instance, flavonoids from natural extracts (e.g., icariin or naringin) were found to stimulate bone tissue regeneration by acting on the BMP signaling pathway, favoring the production of molecules closely related to bone metabolism, including ALP, OSC, and OPN [32-35]. Likewise, daidzein, a soy phytoestrogen, was reported to stimulate osteoblast proliferation and differentiation by activating the BMP/Smad signaling pathway [36].

The osteogenic differentiation of mesenchymal cells is regulated by various transcriptional factors such as OSX and RUNX-2/Cbfa1, which are essential for the regulation of genes involved in producing bone extracellular matrix proteins (e.g., ALP, COL-I, bone sialoprotein [BSP], OSC, and OPN) and for the induction of bone mineralization [37]. OSX regulates the expression of osteoblast differentiation markers (e.g., RUNX-2 and osteonectin [OSN]) and is indispensable for bone proliferation, differentiation, and formation [38,39]. The expressions of OSX and RUNX-2 significantly increased by the treatment with each EVOO phenolic compound in our study, except for apigenin, which significantly increased the expression of OSX, although to a lesser extent versus the other studied compounds, but had no significant impact on the RUNX-2 expression. These effects were accompanied by an increase in ALP and OSC expression after all the treatments and by an increase in COL-I and OPN expression after almost all of them. The treatment of MC3T3-E1 murine osteoblast cells with ugonin K, a flavonoid present in the herbaceous fern-like plant Helminthostachys zeylanica, was reported to regulate the expression of RUNX-2 and OSX and enhance ALP activity, BSP and OSC expression, and mineralization [40]. Likewise, salvianolic acid B, a phenolic acid from the Chinese medicinal plant Salvia Miltiorrhiza, was found to increase the expression by mesenchymal cells of ALP, OPN, RUNX-2, and OSC [41]. The increases in the expression of BMP2, COL-I, ALP, and RUNX-2 genes by the cells and in their ALP activity and mineralization were also observed after treatment with extracts of Davallia formosana, a petrophylic fern widely used in traditional Chinese medicine [42]. ALP and COL-I are early matrix mineralization markers, whereas OSC and OPN are osteogenic maturation markers $[43,44]$ that indicate the differentiation and maturation of bone. Taken together, these data suggest that polyphenols in EVOO (e.g., caffeic acid, ferulic acid, coumaric acid, apigenin, and luteolin) may have a beneficial effect on bone physiology, favoring osteoblast maturation and differentiation. 
The in vitro treatment of MG63 osteoblast cells with various EVOO phenolic compounds was found to induce cell maturation by increasing the synthesis of ALP and reducing the expression of antigens involved in osteoblast immune functions, which may contribute to improving bone mineral density [16]. Similar effects were observed in osteoblast cells after treatment with extracts of different polyphenol-rich EVOO varieties (Picual, Arbequina, Picudo, and Hojiblanca), observing a greater impact for oils with higher content of phenolic compounds [17]. According to these studies, osteoblast maturation and differentiation can be increased in vitro by the treatment either with EVOO extracts or with the phenolic fraction isolated from EVOO.

In contrast, an in vitro study found that treatment of mesenchymal cells with high doses $(100 \mu \mathrm{M})$ of hydroxytyrosol reduced the expression of osteoblast differentiation markers and inhibited osteoblastogenesis [45], while the same dose of apigenin was reported to inhibit osteoblast differentiation markers (COL-I production, ALP, and calcium deposits) in osteoblasts of murine origin [46]. Previous studies by our group concluded that the dose level is a determinant factor, with high doses having a toxic effect on cells [6].

In the present study, the expression of RANKL was increased by the treatment with all studied polyphenols, especially luteolin, while the expression of OPG increased by apigenin, ferulic acid, and coumaric acid, but not by luteolin or caffeic acid. RANKL belongs to the family of the tumor necrosis factor (TNF) ligand and is expressed on mesenchymal cells, preosteoblasts, and T cells. The binding of RANKL with its receptor (RANK) stimulates osteoclast activation and differentiation [47]. However, OPG is a RANKL receptor that inhibits osteoclast differentiation and function, because its interaction with RANKL can prevent it from binding to RANK [48]. The increased expression of these markers and the higher OPG/RANKL ratio may result from activation of the Wnt canonical signaling pathway, which would favor bone tissue formation [49]. The phenolic compounds from various vegetable species have been found to promote osteoblast differentiation through the expression of these markers, which are closely related to bone maturation [50-54].

Recent animal studies confirmed that various phenolic compounds in different vegetable species (e.g., eugenol or salicylic acid) exert beneficial effects on bone [55,56]. Further, in vivo studies are required to verify our in vitro findings on the effects on bone metabolism of the phenolic compounds in EVOO.

\section{Conclusions}

These findings suggest that EVOO phenolic compounds (e.g., caffeic acid, ferulic acid, coumaric acid, apigenin, and luteolin) may have a beneficial effect on bone physiology, exerting a stimulatory effect on markers involved in osteoblast proliferation, differentiation and maturation. These results support the protective effect of the phenolic compounds in EVOO against bone pathologies, like osteoporosis. However further research is warranted to explore their usefulness in the management of bone diseases.

Supplementary Materials: The following are available online at http:/www.mdpi.com/2072-6643/11/8/1722/s1, Table S1: Data for the gene expression of osteoblast-related markers. Mean, standard deviation and $p$ value information after treatment with phenolic compounds vs control.

Author Contributions: Conceptualization: R.C. and G.-M.O.; methodology: R.C., G.-M.O. and M.-R.L.; formal analysis: M.-R.L., M.-M.F.J., I.-M.R., D.L.-B.E. and R.-T.J.; investigation: M.-R.L., M.-M.F.J., I.-M.R., D.L.-B.E. and R.-T.J.; data curation: M.-R.L., R.C. and G.-M.O.; writing-original draft preparation: M.-R.L.; writing-review and editing: R.C. and G.-M.O.; validation: M.-R.L., M.-M.F.J., I.-M.R., D.L.-B.E., R.-T.J., R.C. and G.-M.O.

Funding: The work outlined in this article has been partially funded by the Spanish Ministry of Education under FPU fellowship reference FPU15-05635

Acknowledgments: This study was supported by the research group BIO277 (Junta de Andalucía) and Department of Nursing (University of Granada).

Conflicts of Interest: The authors declare no conflicts of interest. 


\section{References}

1. Sofi, F.; Abbate, R.; Gensini, G.F.; Casini, A. Accruing evidence on benefits of adherence to the Mediterranean diet on health: An updated systematic review and meta-analysis. Am. J. Clin. Nutr. 2010, 92, 1189-1196. [CrossRef] [PubMed]

2. Brown, L.; Poudyal, H.; Panchal, S.K. Functional foods as potential therapeutic options for metabolic syndrome. Obes. Rev. 2015, 16, 914-941. [CrossRef] [PubMed]

3. Pérez-Jiménez, F.; Ruano, J.; Perez-Martinez, P.; Lopez-Segura, F.; Lopez-Miranda, J. The influence of olive oil on human health: Not a question of fat alone. Mol. Nutr. Food Res. 2007, 51, 1199-1208. [CrossRef] [PubMed]

4. Kanakis, P.; Termentzi, A.; Michel, T.; Gikas, E.; Halabalaki, M.; Skaltsounis, A.-L. From olive drupes to olive oil. An HPLC-orbitrap-based qualitative and quantitative exploration of olive key metabolites. Planta Med. 2013, 79, 1576-1587. [CrossRef] [PubMed]

5. Ashwell, M. Concepts of Functional Food; International Life Sciences Institute (ILSI) Press: Washington, DC, USA, 2002; ISBN 157-8-81-1457.

6. García-Martínez, O.; De Luna-Bertos, E.; Ramos-Torrecillas, J.; Ruiz, C.; Milia, E.; Lorenzo, M.L.; Jimenez, B.; Sánchez-Ortiz, A.; Rivas, A. Phenolic Compounds in Extra Virgin Olive Oil Stimulate Human Osteoblastic Cell Proliferation. PLoS ONE 2016, 11, e0150045. [CrossRef]

7. Berrougui, H.; Ikhlef, S.; Khalil, A. Extra Virgin Olive Oil Polyphenols Promote Cholesterol Efflux and Improve HDL Functionality. Evid. Based Complement. Alternat. Med. 2015, 2015, 1-9. [CrossRef] [PubMed]

8. Casamenti, F.; Stefani, M. Olive polyphenols: New promising agents to combat aging-associated neurodegeneration. Expert Rev. Neurother. 2017, 17, 345-358. [CrossRef]

9. Boss, A.; Bishop, K.; Marlow, G.; Barnett, M.; Ferguson, L. Evidence to Support the Anti-Cancer Effect of Olive Leaf Extract and Future Directions. Nutrients 2016, 8, 513. [CrossRef]

10. Bernabei, R.; Martone, A.M.; Ortolani, E.; Landi, F.; Marzetti, E. Screening, diagnosis and treatment of osteoporosis: A brief review. Clin. Cases Miner. Bone Metab. 2014, 11, 201-207. [CrossRef]

11. Kanis, J.A. Assessment of Osteoporosis at the Primary Health-Care Level; World Health Organization Collaborating Centre for Classification in Mental Health: Sydney, Australia; University of Sheffield: Sheffield, UK, 2009.

12. Johnell, O.; Kanis, J.A. An estimate of the worldwide prevalence and disability associated with osteoporotic fractures. Osteoporos. Int. 2006, 17, 1726-1733. [CrossRef]

13. Seeman, E. Reduced bone formation and increased bone resorption: Rational targets for the treatment of osteoporosis. Osteoporos. Int. 2003, 14 (Suppl. 3), 2-8. [CrossRef] [PubMed]

14. Takayanagi, H. Osteoimmunology: Shared mechanisms and crosstalk between the immune and bone systems. Nat. Rev. Immunol. 2007, 7, 292-304. [CrossRef] [PubMed]

15. Florencio-Silva, R.; Sasso, G.R.D.S.; Sasso-Cerri, E.; Simões, M.J.; Cerri, P.S. Biology of Bone Tissue: Structure, Function, and Factors That Influence Bone Cells. BioMed Res. Int. 2015, 2015, 421746. [CrossRef] [PubMed]

16. Melguizo-Rodríguez, L.; Manzano-Moreno, F.J; De Luna-Bertos, E.; Rivas, A.; Ramos-Torrecillas, J.; Ruiz, C.; García-Martínez, O. Effect of olive oil phenolic compounds on osteoblast differentiation. Eur. J. Clin. Investig. 2018, 48, e12904. [CrossRef] [PubMed]

17. Melguizo-Rodríguez, L.; Ramos-Torrecillas, J.; Manzano-Moreno, F.J.; Illescas-Montes, R.; Rivas, A.; Ruiz, C.; De Luna-Bertos, E.; García-Martínez, O. Effect of phenolic extracts from different extra-virgin olive oil varieties on osteoblast-like cells. PLoS ONE 2018, 13, e0196530. [CrossRef] [PubMed]

18. Mousavi, S.N.; Koohdani, F.; Eslaminejad, M.B.; Izadi, P.; Eshraghian, M.; Sayahpour, F.A.; Neek, L.S.; Shidfar, F. Extra virgin olive oil in maternal diet increases osteogenic genes expression, but high amounts have deleterious effects on bones in mice offspring at adolescence. Iran. J. Basic Med. Sci. 2016, 19, 1299-1307. [PubMed]

19. Wu, X.; Li, Z.; Yang, Z.; Zheng, C.; Jing, J.; Chen, Y.; Ye, X.; Lian, X.; Qiu, W.; Yang, F.; et al. Caffeic acid 3,4-dihydroxy-phenethyl ester suppresses receptor activator of NF- $\mathrm{kB}$ ligand-induced osteoclastogenesis and prevents ovariectomy-induced bone loss through inhibition of mitogen-activated protein kinase/activator protein 1 and Ca2+-nuclear factor of activated T-cells cytoplasmic 1 signaling pathways. J. Bone Miner. Res. 2012, 27, 1298-1308. [PubMed]

20. Santiago-Mora, R.; Casado-Díaz, A.; De Castro, M.D.; Quesada-Gómez, J.M. Oleuropein enhances osteoblastogenesis and inhibits adipogenesis: The effect on differentiation in stem cells derived from bone marrow. Osteoporos. Int. 2011, 22, 675-684. [CrossRef] 
21. Ragni, E.; Viganò, M.; Rebulla, P.; Giordano, R.; Lazzari, L. What is beyond a qRT-PCR study on mesenchymal stem cell differentiation properties: How to choose the most reliable housekeeping genes. J. Cell. Mol. Med. 2013, 17, 168-180. [CrossRef]

22. Servili, M.; Esposto, S.; Fabiani, R.; Urbani, S.; Taticchi, A.; Mariucci, F.; Selvaggini, R.; Montedoro, G.F. Phenolic compounds in olive oil: Antioxidant, health and organoleptic activities according to their chemical structure. Inflammopharmacology 2009, 17, 1-9. [CrossRef]

23. Manzano-Moreno, F.J.; Medina-Huertas, R.; Ramos-Torrecillas, J.; García-Martínez, O.; Ruiz, C. The effect of low-level diode laser therapy on early differentiation of osteoblast via BMP-2/TGF- $\beta 1$ and its receptors. J. Cranio Maxillofac. Surg. 2015, 43, 1926-1932. [CrossRef] [PubMed]

24. Sun, X.; Cao, Z.; Zhang, Q.; Li, M.; Han, L.; Li, Y. Aluminum trichloride inhibits osteoblast mineralization via TGF- $31 /$ Smad signaling pathway. Chem. Biol. Interact. 2016, 244, 9-15. [CrossRef] [PubMed]

25. Ochiai, H.; Okada, S.; Saito, A.; Hoshi, K.; Yamashita, H.; Takato, T.; Azuma, T. Inhibition of insulin-like growth factor-1 (IGF-1) expression by prolonged transforming growth factor- $\beta 1$ (TGF- $\beta 1$ ) administration suppresses osteoblast differentiation. J. Biol. Chem. 2012, 287, 22654-22661. [CrossRef] [PubMed]

26. Miron, R.J.; Saulacic, N.; Buser, D.; Iizuka, T.; Sculean, A. Osteoblast proliferation and differentiation on a barrier membrane in combination with BMP2 and TGFß1. Clin. Oral Investig. 2013, 17, 981-988. [CrossRef] [PubMed]

27. Lieb, E.; Vogel, T.; Milz, S.; Dauner, M.; Schulz, M.B. Effects of transforming growth factor beta1 on bonelike tissue formation in three-dimensional cell culture. II: Osteoblastic differentiation. Tissue Eng. 2004, 10, 1414-1425. [PubMed]

28. Chen, M.; Dong, Q.R.; Huang, Q.; Xu, W.; She, C. Effects of 0.5 Gy X-ray radiation on the profile of gene expression in MC3T3-E1 osteoblasts. J. Cranio Maxillofac. Surg. 2016, 96, 2659-2664.

29. Wu, H.; Zha, Z.; Yao, P. Experimental study of icariin in inducing bone marrow mesenchymal stem cell differentiation. Zhongguo Zhong Xi Yi Jie He Za Zhi Zhongguo Zhongxiyi Jiehe Zazhi Chin. J. Integr. Tradit. West. Med. 2010, 30, 410-415.

30. Canalis, E.; Economides, A.N.; Gazzerro, E. Bone morphogenetic proteins, their antagonists, and the skeleton. Endocr. Rev. 2003, 24, 218-235. [CrossRef]

31. Urist, M.R. Bone: Formation by autoinduction. Science 1965, 150, 893-899. [CrossRef]

32. Xu, B.; Wang, X.; Wu, C.; Zhu, L.; Chen, O.; Wang, X. Flavonoid compound icariin enhances BMP-2 induced differentiation and signalling by targeting to connective tissue growth factor (CTGF) in SAMP6 osteoblasts. PLoS ONE 2018, 13, e0200367. [CrossRef]

33. Liang, W.; Lin, M.; Li, X.; Li, C.; Gao, B.; Gan, H.; Yang, Z.; Lin, X.; Liao, L.; Yang, M. Icariin promotes bone formation via the BMP-2/Smad4 signal transduction pathway in the hFOB 1.19 human osteoblastic cell line. Int. J. Mol. Med. 2012, 30, 889-895. [CrossRef] [PubMed]

34. Wu, J.-B.; Fong, Y.-C.; Tsai, H.-Y.; Chen, Y.-F.; Tsuzuki, M.; Tang, C.-H. Naringin-induced bone morphogenetic protein-2 expression via PI3K, Akt, c-Fos/c-Jun and AP-1 pathway in osteoblasts. Eur. J. Pharmacol. 2008, 588, 333-341. [CrossRef] [PubMed]

35. Gaoli, X.; Yi, L.; Lili, W.; Qiutao, S.; Guang, H.; Zhiyuan, G. Effect of naringin combined with bone morphogenetic protein-2 on the proliferation and differentiation of MC3T3-E1 cells. Hua Xi Kou Qiang Yi Xue Za Zhi Huaxi Kouqiang Yixue Zazhi West China J. Stomatol. 2017, 35, 275-280.

36. Hu, B.; Yu, B.; Tang, D.; Li, S.; Wu, Y. Daidzein promotes osteoblast proliferation and differentiation in OCT1 cells through stimulating the activation of BMP-2/Smads pathway. Genet. Mol. Res. 2016, 15. [CrossRef] [PubMed]

37. Hinoi, E.; Fujimori, S.; Wang, L.; Hojo, H.; Uno, K.; Yoneda, Y. Nrf2 negatively regulates osteoblast differentiation via interfering with Runx2-dependent transcriptional activation. J. Biol. Chem. 2006, 281, 18015-18024. [CrossRef]

38. Franceschi, R.T.; Xiao, G.; Jiang, D.; Gopalakrishnan, R.; Yang, S.; Reith, E. Multiple signaling pathways converge on the Cbfa1/Runx2 transcription factor to regulate osteoblast differentiation. Connect. Tissue Res. 2003, 44 (Suppl. 1), 109-116. [CrossRef] [PubMed]

39. Nakashima, K.; Zhou, X.; Kunkel, G.; Zhang, Z.; Deng, J.M.; Behringer, R.R.; de Crombrugghe, B. The novel zinc finger-containing transcription factor osterix is required for osteoblast differentiation and bone formation. Cell 2002, 108, 17-29. [CrossRef] 
40. Lee, C.-H.; Huang, Y.-L.; Liao, J.-F.; Chiou, W.-F. Ugonin K promotes osteoblastic differentiation and mineralization by activation of p38 MAPK- and ERK-mediated expression of Runx2 and osterix. Eur. J. Pharmacol. 2011, 668, 383-389. [CrossRef]

41. Xu, D.; Xu, L.; Zhou, C.; Lee, W.Y.W.; Wu, T.; Cui, L.; Li, G. Salvianolic acid B promotes osteogenesis of human mesenchymal stem cells through activating ERK signaling pathway. Int. J. Biochem. Cell Biol. 2014, 51, 1-9. [CrossRef]

42. Wu, C.-F.; Lin, Y.-S.; Lee, S.-C.; Chen, C.-Y.; Wu, M.-C.; Lin, J.-S. Effects of Davallia formosana Hayata Water and Alcohol Extracts on Osteoblastic MC3T3-E1 Cells. Phytother. Res. 2017, 31, 1349-1356. [CrossRef]

43. Rahman, M.S.; Akhtar, N.; Jamil, H.M.; Banik, R.S.; Asaduzzaman, S.M. TGF- $\beta$ /BMP signaling and other molecular events: Regulation of osteoblastogenesis and bone formation. Bone Res. 2015, 3, 15005. [CrossRef] [PubMed]

44. Stein, G.S.; Lian, J.B.; Stein, J.L.; van Wijnen, A.J.; Frenkel, B.; Montecino, M. Mechanisms Regulating Osteoblast Proliferation and Differentiation. In Principles of Bone Biology; Bilezikian, J.P., Raisz, L.G., Rodan, G.A., Eds.; Academic Press: San Diego, CA, USA, 1996.

45. Anter, J.; Quesada-Gómez, J.M.; Dorado, G.; Casado-Díaz, A. Effect of Hydroxytyrosol on Human Mesenchymal Stromal/Stem Cell Differentiation into Adipocytes and Osteoblasts. Arch. Med. Res. 2016, 47, 162-171. [CrossRef] [PubMed]

46. Goto, T.; Hagiwara, K.; Shirai, N.; Yoshida, K.; Hagiwara, H. Apigenin inhibits osteoblastogenesis and osteoclastogenesis and prevents bone loss in ovariectomized mice. Cytotechnology 2015, 67, 357-365. [CrossRef] [PubMed]

47. Ikeda, T.; Utsuyama, M.; Hirokawa, K. Expression profiles of receptor activator of nuclear factor kappaB ligand, receptor activator of nuclear factor kappaB, and osteoprotegerin messenger RNA in aged and ovariectomized rat bones. J. Bone Miner. Res. 2001, 16, 1416-1425. [CrossRef] [PubMed]

48. Khosla, S. Minireview: The OPG/RANKL/RANK system. Endocrinology 2001, 142, 5050-5055. [CrossRef] [PubMed]

49. Hu, Z.; Lin, D.; Qi, J.; Qiu, M.; Lv, Q.; Li, Q.; Lin, Z.; Liao, Z.; Pan, Y.; Jin, O.; et al. Serum from patients with ankylosing spondylitis can increase PPARD, fra-1, MMP7, OPG and RANKL expression in MG63 cells. Clinics 2015, 70, 738-742. [CrossRef]

50. Satué, M.; del Mar Arriero, M.; Monjo, M.; Ramis, J.M. Quercitrin and taxifolin stimulate osteoblast differentiation in MC3T3-E1 cells and inhibit osteoclastogenesis in RAW 264.7 cells. Biochem. Pharmacol. 2013, 86, 1476-1486.

51. Srivastava, S.; Bankar, R.; Roy, P. Assessment of the role of flavonoids for inducing osteoblast differentiation in isolated mouse bone marrow derived mesenchymal stem cells. Phytomedicine 2013, 20, 683-690. [CrossRef]

52. Xiao, H.-H.; Gao, Q.-G.; Zhang, Y.; Wong, K.-C.; Dai, Y.; Yao, X.-S.; Wong, M.-S. Vanillic acid exerts oestrogen-like activities in osteoblast-like UMR 106 cells through MAP kinase (MEK/ERK)-mediated ER signaling pathway. J. Steroid Biochem. Mol. Biol. 2014, 144 Pt B, 382-391. [CrossRef]

53. Kim, M.-B.; Song, Y.; Hwang, J.-K. Kirenol stimulates osteoblast differentiation through activation of the $\mathrm{BMP}$ and Wnt/ $\beta$-catenin signaling pathways in MC3T3-E1 cells. Fitoterapia 2014, 98, 59-65. [CrossRef]

54. Xiao, H.-H.; Fung, C.-Y.; Mok, S.-K.; Wong, K.-C.; Ho, M.-X.; Wang, X.-L.; Yao, X.-S.; Wong, M.-S. Flavonoids from Herba epimedii selectively activate estrogen receptor alpha $(E R \alpha)$ and stimulate ER-dependent osteoblastic functions in UMR-106 cells. J. Steroid Biochem. Mol. Biol. 2014, 143, 141-151. [CrossRef] [PubMed]

55. Tanaka, T.; Kawaguchi, N.; Zaima, N.; Moriyama, T.; Fukuta, Y.; Shirasaka, N. Antiosteoporotic activity of a syringic acid diet in ovariectomized mice. J. Nat. Med. 2017, 71, 632-641. [CrossRef] [PubMed]

56. Abuohashish, H.M.; Khairy, D.A.; Abdelsalam, M.M.; Alsayyah, A.; Ahmed, M.M.; Al-Rejaie, S.S. In-vivo assessment of the osteo-protective effects of eugenol in alveolar bone tissues. Biomed. Pharmacother. 2018, 97, 1303-1310. [CrossRef] [PubMed]

(C) 2019 by the authors. Licensee MDPI, Basel, Switzerland. This article is an open access article distributed under the terms and conditions of the Creative Commons Attribution (CC BY) license (http://creativecommons.org/licenses/by/4.0/). 